\title{
A REVIEW ON COVID-19: ORIGIN, SYMPTOMS, PRECAUTION, AND RECENT UPDATE OF COVID-19 AND DATABASE SURVEY OF EIGHT COUNTRIES ON PANDEMIC CORONAVIRUS DISEASE
}

\author{
DYADE GK ${ }^{1 *}$, CHANDGUDE SHRUSHTI ${ }^{2}$, DYADE DEEKSHA ${ }^{3}$, CHANDGUDE PRASAD ${ }^{4}$
}

${ }^{1}$ Department of Postgraduate, SVPM College of Pharmacy, Malegaon (BKII), Baramati, Pune, Maharashtra, India, ${ }^{2}$ Ashwini Rural Medical College Hospital and Research Centre, Kumbhari, Solapur, Maharashtra, India, ${ }^{3}$ Department of MBBS, Dr. Vaishampayan Memorial Government Medical College, Solapur, Maharashtra, India, ${ }^{4}$ Department of PG in Dairy Technology, SMC College of Dairy Science, Anand, Gujarat, India. Email: dyadegk@gmail.com

Received: 14 May 2020, Revised and Accepted: 18 June 2020

\section{ABSTRACT}

Coronavirus disease 2019 (COVID-19) is a communicable disease caused with newly discovered severe acute respiratory syndrome coronavirus 2 (SARS-CoV-2). The virus that causes COVID-19 is mainly transmitted through droplets generated when an infected person coughs, sneezes, or exhales. These droplets are too heavy to suspend in the air and quickly fall on floors or surfaces. Persons can be infected by touching contaminated surface and then to touching their eyes, nose, or mouth. This disease since December 2019 when first was identified spread globally, resulting in the on-going 2019-20 coronavirus pandemic. As of May 8, 2020, more than 3,916,338 cases have been reported across 185 countries and territories, resulting in more than 270,711 deaths. More than 1,343,054 people have recovered. The purpose of this review article was to study preventive and measurable actions implemented by the respective countries nationwide to prevent COVID-19's severity, spread, and mortality. The most affected nations were the USA, Spain, Italy, the UK, France, and Germany, and less affected India, whereas countries like New Zealand were not much affected. To this date, India was able to control spread of COVID-19 due to early measurable preventive control on this disease. The study including recovered rate of disease, growth rate of disease, and mortality rate was carried out for these countries. The study proved that measurable actions such as lockdown imposing and social distance maintenance were effective to prevent spread of COVID-19 and would be effective, as currently, there is no vaccine or specific antiviral treatment for this.

Keywords: COVID-19, SARS, Pandemic, Virus, Lockdown.

\section{INTRODUCTION}

\section{Origin and spread}

Coronavirus disease 2019 (COVID-19) is an infectious disease cause by severe acute respiratory syndrome coronavirus 2 (SARS-CoV-2). The disease was first recognized in December 2019 in Wuhan, the capital of China's Hubei region, and has since spread globally, resulting in the ongoing 2019-20 coronavirus pandemic [1]. A molecular dating estimate based on the SARS-CoV-2 genomic sequences indicates an origin in November. This raises questions about the link between this COVID-19 epidemic and wildlife.

The virus is primarily spread between people throughout close contact, often through small droplets produced by coughing, sneezing, or talking. The droplets usually drop to the ground or onto surfaces rather than remaining in the air over long distances. People may also become infected by touching a contaminated surface and then touching their face. In experimental settings, the virus may survive on surfaces for up to $72 \mathrm{~h}$. It is most infectious during the first 3 days after the onset of symptoms, although spread may be possible before symptoms appear and in later stages of the disease. Most people infected with the COVID-19 virus will experience mild-to-moderate respiratory illness and get well without requiring special treatment. Older people and those with underlying medical problems such as cardiovascular disease, diabetes, chronic respiratory disease, and cancer are more likely to develop serious illness [2].

\section{Common symptoms}

The COVID-19 virus affects different people in different ways. COVID-19 is a respiratory disease and most infected people will develop mild-to-moderate symptoms and recover without requiring special treatment. People who have fundamental medical conditions and those over 60 years old have a higher risk of developing severe disease and death
Common symptoms include

- Fever

- Tiredness and fatigue

- Dry cough

- Loss of smell

Other symptoms include

- Shortness of breath

- Aches and pains

- Sore throat

- And very few people will report diarrhea, nausea, or a runny nose.

While the majority of cases result in mild symptom, some progress to viral pneumonia, multiorgan failure, or cytokine storm [3]. More concerning symptoms include difficulty breathing, persistent chest pain, confusion, difficulty waking, and bluish skin [4]. The time from contact to onset of symptoms is typically around 5 days but may range from 2 to 14 days [5].

\section{Diagnosis}

The standard method of diagnosis is by real-time reverse transcription polymerase chain reaction (rRT-PCR) from a nasopharyngeal swab. Chest CT imaging might also be helpful for diagnosis in individuals where there is a high suspicion of infection based on symptoms and risk factors; however, guidelines do not recommend using it for routine screening [6].

Recommended measures to prevent infection include $[7,8]$

- Frequent handwashing with soap and water, or clean them with alcohol-based hand rub.

- Maintaining physical distance from others (especially from those by means of symptoms),

- Cover your lips and nose when coughing or sneezing, and keeping unwashed hands away from the face.

- Stay home if you feel unwell. 
- Refrain from smoking and other activities so as to weaken the lungs.

- Practice physical distancing by avoiding needless travel and staying away from large groups of people.

In addition, the use of a face covering is recommended for those who suspect they have the virus and their caregivers. Recommendations for face covering use by the general public vary, with some authorities recommending against their use, some recommending their use, and others requiring their use. At present, there is not sufficient evidence for or against the use of masks (medical or other) in healthy individuals in the wider community.

\section{Risk factors}

Without taking proper prevention measures, peoples are also at high risk if

- Live with someone who has contracted the virus

- Are providing home care for a big shot who has contracted the virus

- Have an intimate partner who has thin the virus

Older people and people with certain health conditions have a higher risk for severe complications if they contract the virus. These health conditions include:

- Lung conditions, such as COPD and asthma

- Certain heart conditions

- Resistant system conditions, such as HIV

- Cancer that requires treatment

- Severe obesity

- Other health conditions, if not well-controlled, such as diabetes, kidney disease, or liver disease

- Pregnant women have a higher risk of complications from other viral infections, but it's not yet known if this is the case for COVID-19.

\section{Virology}

Severe acute respiratory syndrome coronavirus 2 (SARS-CoV-2) is a novel severe acute respiratory syndrome coronavirus, primary isolated from three people with pneumonia connected to the clustery of acute respiratory illness cases in Wuhan [9]. All kinds of the novel SARSCoV-2 virus occur in related coronaviruses in nature [10]. Outside the person body, the virus is killed by household soap, which bursts its protective bubble [6].

\section{Genomic data}

The SARS-CoV-2 (Fig. 1) genome was rapidly sequenced by Chinese researchers. It is an RNA molecule of about 30,000 bases containing 15 genes, including the $\mathrm{S}$ gene which codes for a protein located on the surface of the viral envelop [11].

SARS-CoV-2 is closely related to the original SARS-Co [12]. It is thought to have a zoonotic origin. Genetic analysis has revealed the coronavirus hereditarily clusters with the genus Betacoronavirus, in subgenus Sarbecovirus (lineage B) jointly with two bat-derived strains. It is $96 \%$ identical at the whole genome height to other bat coronavirus sample (BatCov RaTG13) [13]. In February 2020, Chinese researchers establish that there is only one amino acid difference in the binding domain of the $S$ protein between the coronaviruses from pangolins and those from humans; though, whole-genome comparison to date establish that at most $92 \%$ of genetic material was shared between pangolin coronavirus and SARS-CoV-2, which is insufficient to show pangolins to be the intermediate host [14].

\section{Current treatment and therapies [15]}

Examples of therapies used for these illnesses include

- As mechanical ventilation

- Steroids to reduce lung antiviral or retroviral medications

- Breathing support, such swelling

- Blood plasma transfusions.

At present, there is no vaccine or specific antiviral treatment for COVID-19. Management involves the treatment of symptoms, supportive care, isolation, and new measures. The World Health Organization (WHO) declared the 2019-20 coronavirus outbreak a Public Health Emergency of International Concern (PHEIC) on January 30, 2020, and a pandemic on March 11, 2020. Local transmission of the disease has occurred in mainly countries across all six WHO regions.

Recent update on development of vaccine [16]

- The US-based Pharma giant Pfizer has already injected the first experimental vaccine on patients. Remdesivir has been showing "very promising" results as antiviral drug in a crucial study in the US.

- Israel government's Institute for Biological Research (IIBR) has developed an antibody to the novel coronavirus and is going to patent and mass produce the potential treatment.

- In China, the US-based Inovio Pharmaceuticals has attempted DNAbased vaccine. Chinese vaccines are under fast development and now undergoing Phase 1 and Phase 2 human trials includes CanSino Biological Inc.-Beijing Institute of Biotechnology, Wuhan Institute of Biological Products-Sinopharm, Beijing Institute of Biological Products with Sinopharm, and an independent SARS platform-based inactivated vaccine from Sinovac.

- Serum biological Institute, Pune, Maharashtra (India), collaboration with Oxford team has started human trials of a vaccine produced.

\section{Global strategy to respond to COVID-19 [17]}

The overarching goal is for all countries to manage the pandemic by slowing down the transmission and reducing mortality associated with COVID-19. The global strategic objectives are as follows:

- Mobilize all sectors and communities to make sure that every division of government and society takes ownership of and participate in the response and in preventing cases through hand hygiene, respiratory etiquette, and individual level physical distancing.

- Control sporadic cases and clusters and prevent community broadcast by fast finding and isolating all cases, providing them with suitable care, and tracing, quarantining, and supporting all contacts.

- Suppress neighborhood transmission through context-appropriate infection prevention and control measures, population level physical distancing measures, and appropriate and proportionate limits on non-essential domestic and global travel.

- $\quad$ Reduce mortality by providing suitable clinical care for those pretentious by COVID19, ensuring the continuity of essential health and social services, and protecting frontline workers and vulnerable populations.

- Develop safe and effectual vaccines and therapeutics that can be deliver at scale and that are accessible based on need.

\section{Country wise data reviewed up to May 7, 2020 [15,17-19]}

Country wise data related to first case of disease, first death reported, measurable preventive actions, and present situation of the disease spread was reviewed

\section{USA [18,19]}

The first U.S. case of COVID-19 was reported on January 20, 2020, in a man who had returned from Wuhan, China to Washington on January 15, 2020. The first report of the U.S. death came on February 29, 2020. Earlier the first known U.S. death from COVID-19 occurred on February 6, 2020, in Santa Clara colony, California, but it was reported in late April. On January 31, 2020, the USA administration through the U.S. Department of Health and Human Services declared a public health emergency and imposed mandatory 14 days quarantine for any U.S. citizens who have visited Hubei Province in China within preceding 2 weeks. It also began denying entry of non-US. The total cases and total death are graphically represented in Fig. 2.

\section{Spain $[18,20]$}

The COVID-19 pandemic was confirmed to have increase to Spain on January 31, 2020, when a German tourist tested positive for SARSCoV-2 in La Gomers, Canary Islands. On February 13, 2020, the first death in Spain was recorded involving a 69-year-old man who had been in Nepal. He died in Valencia and was diagnosed postmortem. By March 
13,2020 , cases had been confirmed in all 50 provinces of the country. A state of alarm and nationwide lockdown was imposed on March 14 2020. On March 29, it was announced that all non-essential workers were to stay home for the next 14 days. The total cases and total death are graphically represented in Fig. 3.

\section{Italy $[\mathbf{1 8 , 2 1}$}

COVID-19 was first confirmed to have spread to Italy on January 31 2020, when two Chinese tourists in Rome tested positive for the virus.

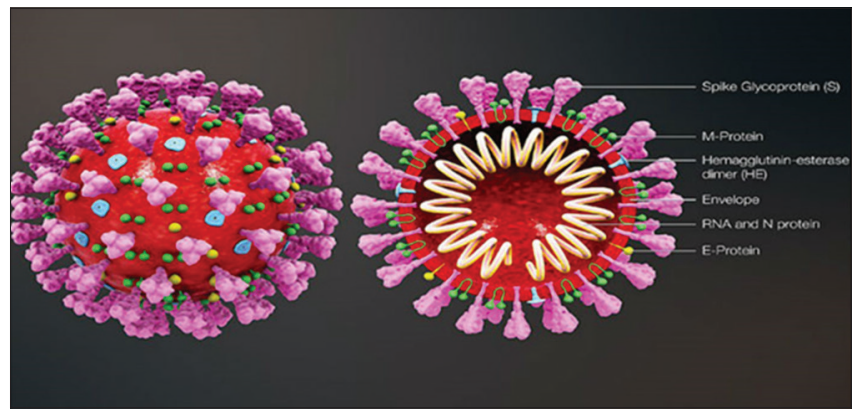

Fig. 1: The diagram of Coronavirus
First death was confirmed on February 22, 2020. On January 31, the govt. suspended all flights to and from China and declared a state of emergency. On March 9, 2020, govt. ordered quarantine to all Italy. On March 21, Italian govt. closed all non-essential business and industries and restricted movement of people. The total cases and total death are graphically represented in Fig. 4.

\section{United Kingdom UK [18,22]}

COVID-19 spread to the UK in late January 2020. On January 31, 2020, two cases were confirmed in the UK. On March 5, 2020, the first death reported in the UK. On March 20, 2020, all schools, restaurants, pubs, clubs, and indoor leisure facilities were ordered to shut. On March 23, the govt. imposed a lockdown on the whole population banning all non-essential travel and contact with people outside one's home, and shutting almost all business, venues, facilities, and places of worship.

The total cases and total death are graphically represented in Fig. 5.

\section{France [18,23]}

COVID-19 pandemic reached France on January 24, 2020, when the first COVID-19 case in Europe and France was confirmed in Bordeaux. The first five confirmed cases be all individuals who had recently arrived or returned from China. A Chinese traveler who was admitted to hospital

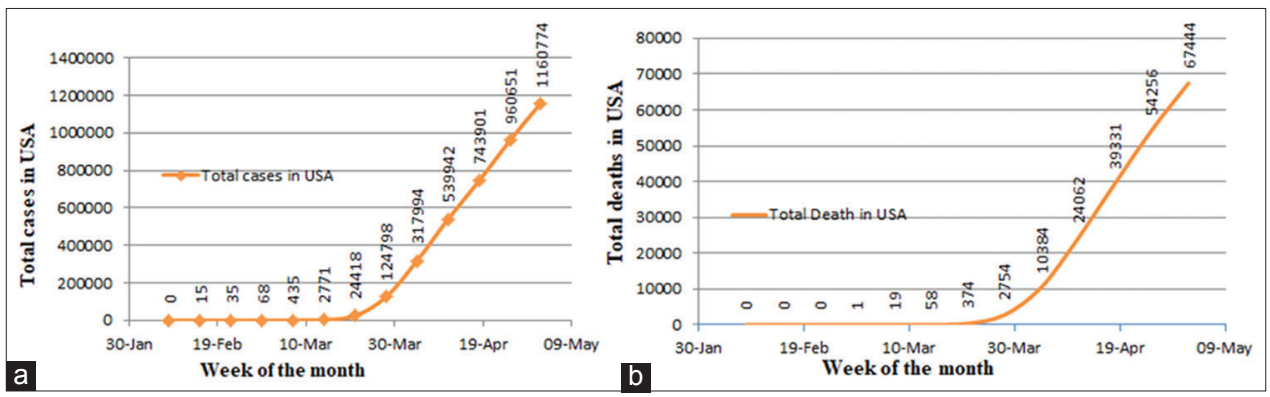

Fig. 2: (a) Total cases of COVID-19 infected and (b) death in the USA per week from February 5, 2020

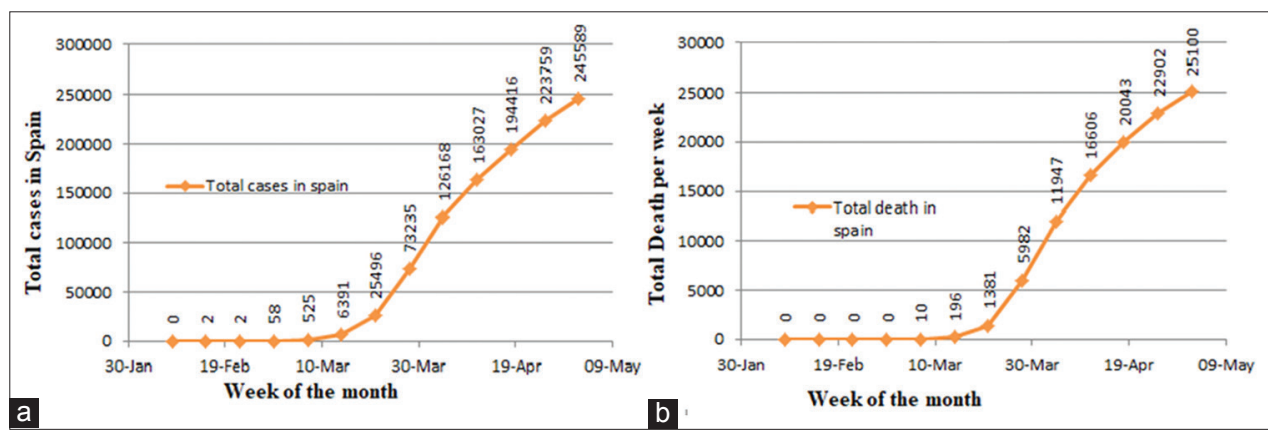

Fig. 3: (a) Total cases of COVID-19 infected and (b) death in Spain per week from February 5, 2020

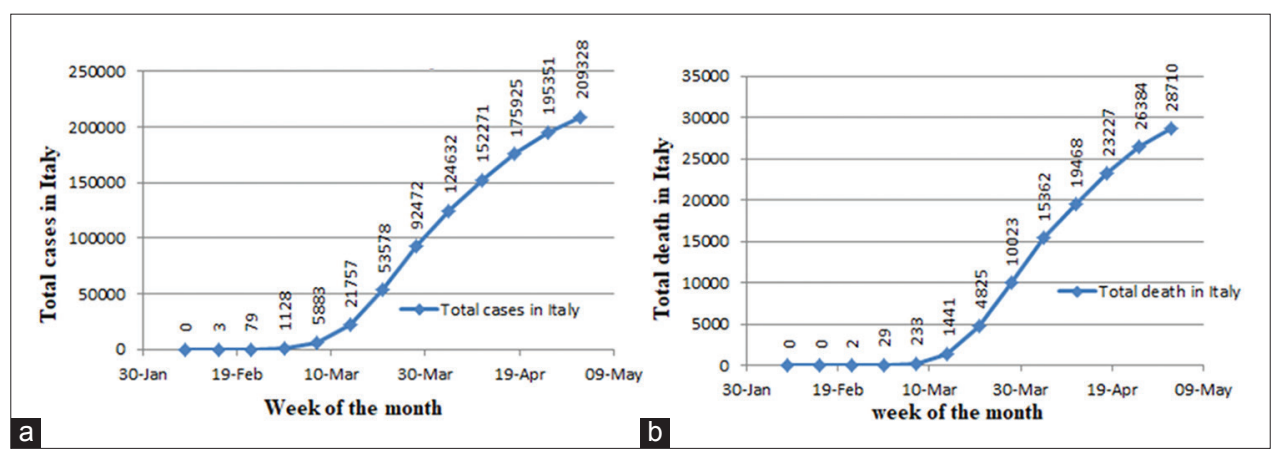

Fig. 4: (a) Total cases of COVID-19 infected and (b) death in Italy per week from February 5, 2020 
in Paris on January 28, 2020, then died on February 14 making it the first COVID-19 death in France. On March 12, the govt. in France announced on public television that all schools and all universities would close from Monday March 16, 2020, until further notice. On March 16, 2020, govt. announced mandatory home confinement for 15 days starting on March 17. This was extended twice until May 11, 2020. The total cases and total death are graphically represented in Fig. 6.

\section{Germany $[18,24]$}

The on-going COVID-19 pandemic spread to Germany on January 27, 2020, when the first case was confirmed and contained near Munich, Bavaria. On February 25 and 26, multiple cases connected to the Italian outbreak be detected in Baden. The first death was reported on March 9, 2020. German disease and epidemic control are advised by the Robert Koch Institute (RKI) according to a national pandemic plan. Since March 13, the pandemic has been managed in the protection stage as per the RKI plan, with German states mandate school and kindergarten closures, postponing academic semesters, and prohibiting visits to nursing homes to protect the elderly. Two days later, borders to five neighboring countries were closed. By March 22 , all regional governments had announced curfews or restrictions in public spaces. The total cases and total death are graphically represented in Fig. 7.

\section{India $[18,25]$}

On January 30, 2020, India reported its first case of COVID-19 in Kerala, which rose to three cases by February 3, 2020; all were students who had returned from Wuhan, China. No significant rise in cases was seen in the rest of February 2020. On March 4, 2020, 22 new cases came to light, including those of an Italian tourist group with 14 infected members. On March 12, 2020, a 76-year-old man who had returned from Saudi Arabia became the first victim of the virus in the country.

On March 22, 2020, India observed a $14 \mathrm{~h}$ voluntary public curfew at the instance of the govt. The government followed it up with lockdowns in 75 districts where COVID cases had occurred as well as all major cities. Further, on March 24, 2020, the govt. ordered a nationwide lockdown for 21 days, affecting the entire 1.3 billion population of India. On April 14, 2020, the govt. extended the on-going nationwide lockdown till May 3, 2020. The total cases and total death are graphically represented in Fig. 8.

\section{New Zealand $[18,26]$}

New Zealand confirmed its first case on February 28, 2020, a New Zealand citizen in her 60s who had recently visited Iran, returning through Bali, Indonesia, and arriving in New Zealand on February 26, 2020, at Auckland. She had two tests for COVID-19 that was negative, but a third test using a more specific sample was positive. She was

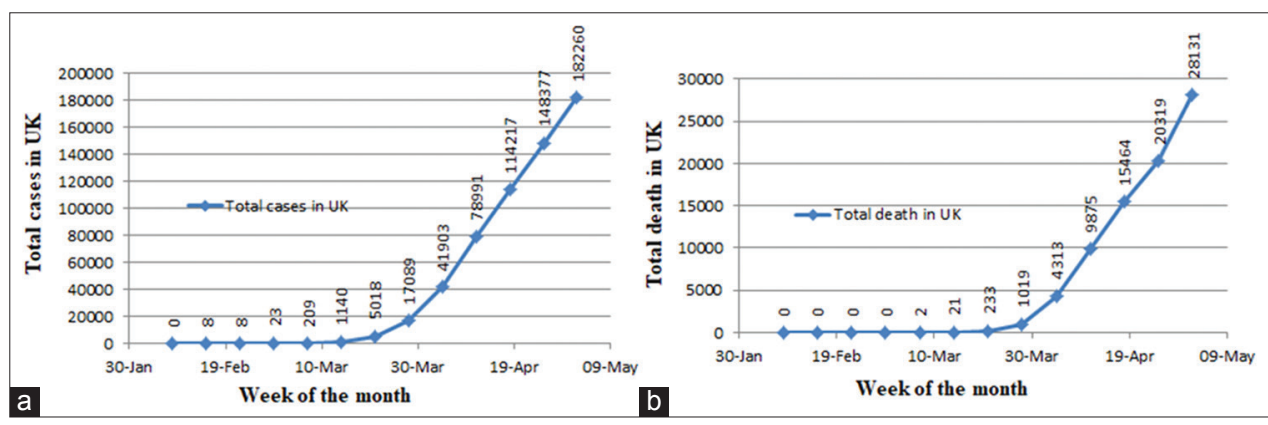

Fig. 5: (a) Total cases of COVID-19 infected and (b) death in the UK per week from February 5, 2020

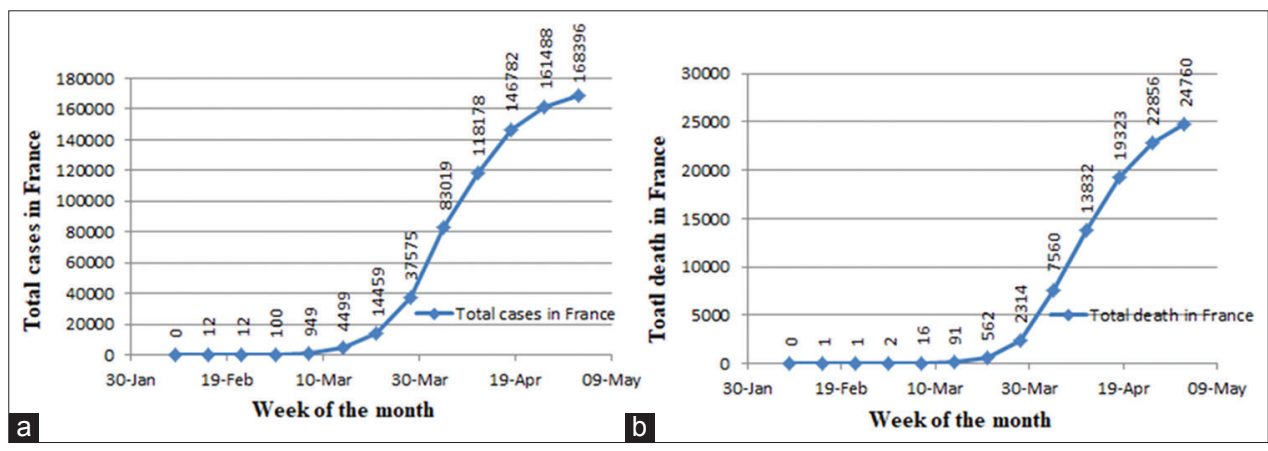

Fig. 6: (a) Total cases of CoVID-19 infected and (b) death in France per week from February 5, 2020

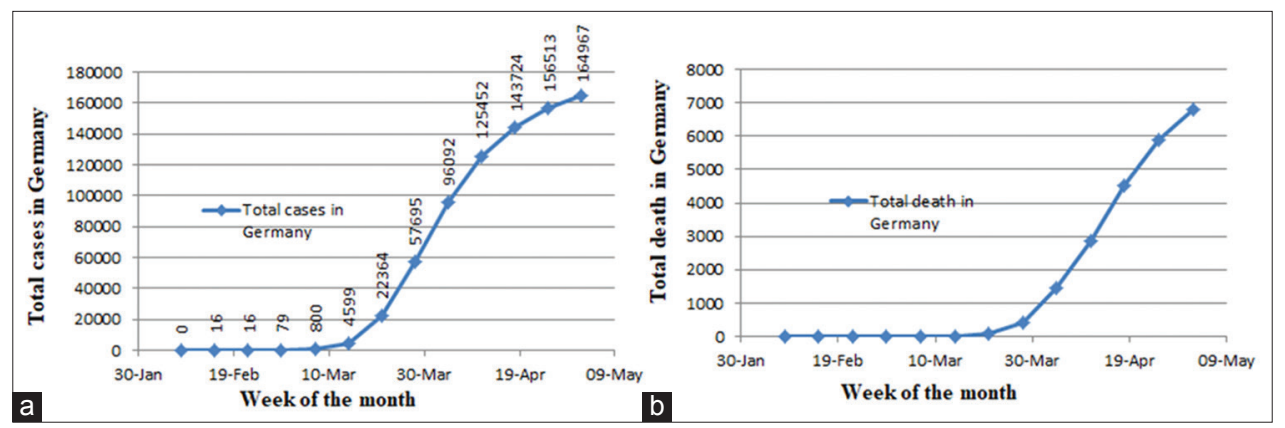

Fig. 7: (a) Total cases of COVID-19 infected and (b) death in Germany per week from February 5, 2020 


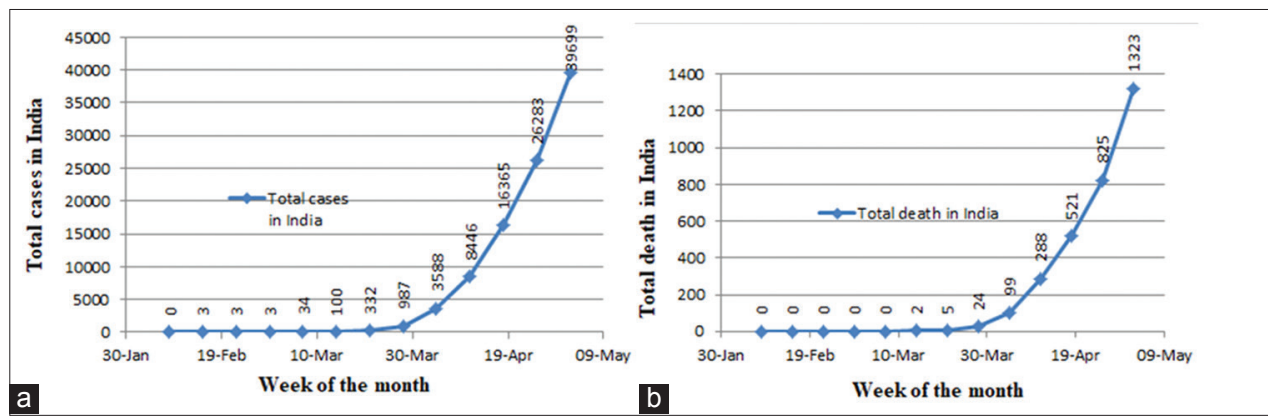

Fig. 8: (a) Total cases of COVID-19 infected and (b) death in India per week from February 5, 2020

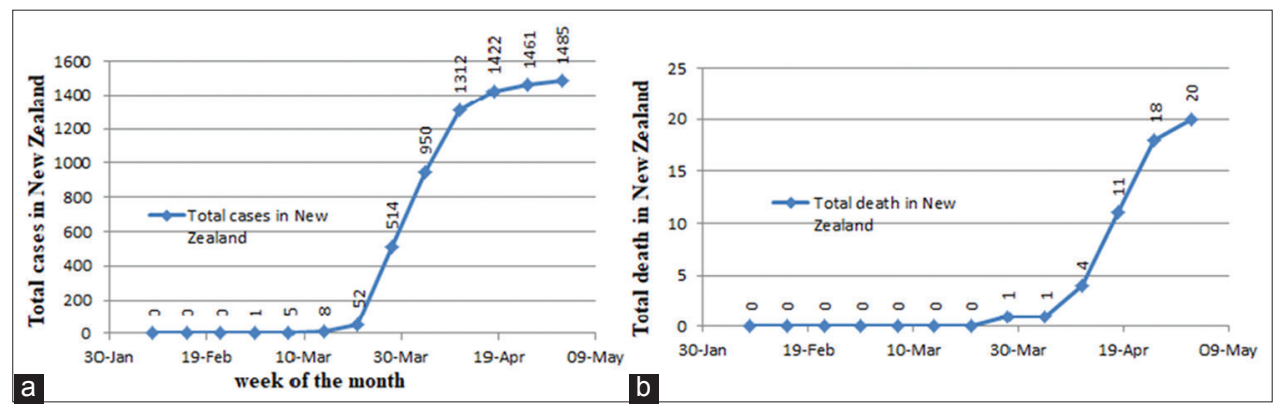

Fig. 9: (a) Total cases of COVID-19 infected and (b) death in New Zealand per week from February 5, 2020

Table 1: 8 Country wise CoVID-19 data [18,19-26]

\begin{tabular}{|c|c|c|c|c|c|c|c|c|}
\hline Country name & USA & Spain & Italy & UK & France & Germany & India & New Zealand \\
\hline \multicolumn{9}{|l|}{ Data } \\
\hline Total cases reported & $1,263,092$ & 253,682 & 214,457 & 201,101 & 174,191 & 168,162 & 52,987 & 1483 \\
\hline \multirow{2}{*}{$\begin{array}{l}\% \text { of (May 6, April 21, } \\
\text { April 6) recovered }\end{array}$} & $74.01 \%$ & $86.04 \%$, & $75.35 \%$ & NA & $67.65 \%$ & $94.98 \%$ & $89.51 \%$ & \multirow[t]{2}{*}{ NA } \\
\hline & $\begin{array}{l}64.55 \% \\
5988 \%\end{array}$ & $\begin{array}{l}79.77 \% \\
75.19 \%\end{array}$ & $\begin{array}{l}67.67 \%, \\
58.02 \%\end{array}$ & & $65.33 \%$, & $94.93 \%$, & $86.04 \%$, & \\
\hline Total mortality & $\begin{array}{l}59.88 \% \\
74799\end{array}$ & $\begin{array}{l}75.19 \% \\
25851\end{array}$ & $\begin{array}{l}58.02 \% \\
29684\end{array}$ & 30076 & $\begin{array}{l}65.94 \% \\
25809\end{array}$ & $\begin{array}{l}94.0 \% \% \\
7275\end{array}$ & $\begin{array}{l}73.39 \% \\
1787\end{array}$ & 21 \\
\hline \multirow{3}{*}{$\begin{array}{l}\% \text { of death in (May 6, } \\
\text { April 21, April 6) }\end{array}$} & $5.92 \%$, & $10.19 \%$ & $13.84 \%$ & $14.95 \%$, & $14.816 \%$, & $4.326 \%$, & $3.372 \%$, & $1.41 \%$, \\
\hline & $1.88 \%$ & $10.42 \%$, & $13.39 \%$, & $15.67 \%$, & $13.545 \%$, & $3.426 \%$ & $3.212 \%$ & $0.089 \%$ \\
\hline & $3.513 \%$ & $9.76 \%$ & $12.46 \%$ & $12.46 \%$ & $9.857 \%$ & $1.751 \%$ & $2.846 \%$ & $0.09 \%$ \\
\hline
\end{tabular}

NA: Data not available

admitted to Auckland city. The first case of the pandemic of COVID-19 in New Zealand was reported on February 28, 2020. On February 3, the New Zealand Government announce that foreign travelers who left from China would be denied entry to New Zealand, with only New Zealand citizens and permanent residents and their family being allowed to enter. On March 21, the govt. announced the foreword of a countrywide alert level system, similar to the existing fire warning systems. There are four levels, with 1 being the least risk of infection and 4 the highest. At the time of the announcement, New Zealand was at level 2. Each level brings added restrictions on activities or movements. Each region can have an individual alert level based on the severity of their infections, and these levels can be changed at any time. The total cases and total death are graphically represented in Fig. 9.

\section{RESULTS AND CONCLUSION}

In many countries, COVID-19 was first detected in January. In March and April, total cases were increased though stringent remedy implemented by all these countries to prevent and spread of pandemic disease. Data of April 21-May 6 period show decrease in death rate as compare to data of April 6-April 21 period show expected results due to preventive action by countries globally. Recovery data of each country were shown gradual increase in recovery rate to May 6. Table 1 shows updated data on May 7, 2020.
It is concluded that measurable prevention took by these nations were appreciably increased the recovery rate and decreased daily outcome total cases of COVID-19. At present, social distance maintaining and selfquarantine are worthy remedy to avoid and keep away from COVID-19.

\section{REFERENCES}

1. Hui DS, Azhar EI, Madani TA, Ntoumi F, Kock R, Dar O, et al. The continuing 2019-nCOV epidemic threat of novel coronavirus to global health-the latest 2019 novel coronavirus outbreak in Wuhan China. Int J Infect Dis 2020;91:264-66.

2. Available from: https:/www.who.int/health-topics/coronavirus.

3. Mehta P, McAuley DF, Brown M, Sanchez E, Tattersall RS, Manson JJ. COVID-19: Consider cytokine storm syndromes and immunosuppression. Lancet 2020;395:1033-4.

4. Centers for Disease Control and Prevention. Symptoms of Coronavirus. U.S. United States: Centers for Disease Control and Prevention; 2020.

5. Velavan TP, Meyer CG. The COVID-19 epidemic. Trop Med Int Health 2020;25:278-80.

6. Salehi S, Abedi A, Balakrishnan S, Gholamrezanezhad A. Coronavirus disease 2019 (COVID-19): A systematic review of imaging findings in 919 patients. Am J Roentgenol 2020;214:1287-94.

7. Available from: https://www.who.int/emergencies/diseases/novelcoronavirus-2019/global-research-on-novel-coronavirus-2019-ncov.

8. Shuo F, Chen S, Nan X, Wei S, Mengzhen F, Benjamin JC. Rational use of face masks in the COVID-19 pandemic. Lancet Respir Med 
2020;8:434-6.

9. Outbreak of Severe Acute Respiratory Syndrome Coronavirus 2 (SARS CoV-2): Increased Transmission Beyond China- $4^{\text {th }}$ Update. European Centre for Disease Prevention and Control; 2020. Available from: https://www.ecdc.europa.eu/en/publications-data/outbreak-severeacute-respiratory-syndrome-coronavirus-2-sars-cov-2-increased. [Last accessed on 2020 Mar 8].

10. Andersen KG, Rambaut A, Lipkin WI, Holmes EC, Garry RF. The proximal origin of SARS-CoV-2. Nat Med 2020;26:450-2

11. Available from: https://www.who.int/emergencies/diseases/novelcoronavirus-2019/technical-guidance/infection-prevention-andcontrol.

12. Zhu N, Zhang D, Wang W, li X, Yang B, Song J, et al. A novel coronavirus from patients with pneumonia in china, 2019. N Engl J Med 2020;382:727-33.

13. Report of the WHO-China Joint Mission on Coronavirus Disease 2019 (COVID-19). World Health Organization; 2020. Available from: ??? [Last accessed on 2020 Mar 21]
14. Cyranoski D. Mystery deepens over animal source of coronavirus. Nature 2020;579:18-9.

15. Available from: https://www.who.int/diseases/coronavirus.

16. Available from: https://www.en.wikipedia.org/wiki/COVID-19 vaccine.

17. Available from: https://www.who.int/docs/default-source/coronaviruse/ covid-strategy-update-2020.

18. Available from: https://www.en.wikipedia.org/wiki/2020_coronavirus pandemic in

19. Available from: https://www.worldometers.info/coronavirus/USA

20. Available from: https://www.worldometers.info/coronavirus/Spain

21. Available from: https://www.worldometers.info/coronavirus/Italy.

22. Available from: https://www.worldometers.info/coronavirus/United Kingdom.

23. Available from: https://www.worldometers.info/coronavirus/France.

24. Available from: https://www.worldometers.info/coronavirus/Germany.

25. Available from: https://www.worldometers.info/coronavirus/India.

26. Available from: https://www.worldometers.info/coronavirus/New Zealand 